\title{
Immunological and toxicological risk assessment of e-cigarettes
}

\author{
Gagandeep Kaur ${ }^{1,3}$, Rakeysha Pinkston ${ }^{1,3}$, Benathel Mclemore ${ }^{1}$, \\ Waneene C. Dorsey ${ }^{2}$ and Sanjay Batra ${ }^{1}$
}

Affiliations: 'Laboratory of Pulmonary Immuno-toxicology, Dept of Environmental Toxicology, Health Research Center, College of Sciences and Engineering, Southern University and A\&M College, Baton Rouge, LA, USA. ${ }^{2}$ Dept of Biological Sciences, College of Arts and Sciences, Grambling State University, Grambling, LA, USA. ${ }^{3}$ Both authors contributed equally.

Correspondence: Sanjay Batra, 207 Health Research Center, Dept of Environmental Toxicology, Southern University and A\&M College, Baton Rouge, LA 70813, USA. E-mail: sanjay_batrađsubr.edu

@ERSpublications

A critical review outlining the toxicological profile and immunological consequences of e-cigarette use http://ow.ly/y3ee30hH2aB

Cite this article as: Kaur G, Pinkston R, Mclemore B, et al. Immunological and toxicological risk assessment of e-cigarettes. Eur Respir Rev 2018; 27: 170119 [https://doi.org/10.1183/16000617.0119-2017].

ABSTRACT Knowledge of the long-term toxicological and immunological effects of e-cigarette (e-cig) aerosols remains elusive due to the relatively short existence of vaping. Therefore, we performed a systematic search of articles published in public databases and analysed the research evidence in order to provide critical information regarding e-cig safety. Electronic nicotine delivery systems (or e-cigs) are an alternative to traditional cigarettes for the delivery of nicotine and are typically filled with glycerol or propylene glycol-based solutions known as e-liquids. Though present in lower quantities, e-cig aerosols are known to contain many of the harmful chemicals found in tobacco smoke. However, due to the paucity of experimental data and contradictory evidence, it is difficult to draw conclusive outcomes regarding toxicological, immunological and clinical impacts of e-cig aerosols. Excessive vaping has been reported to induce inflammatory responses including mitogen-activated protein kinase, Janus tyrosine kinase/signal transducer and activator of transcription and nuclear factor- $\kappa \mathrm{B}$ signalling, similar to that induced by tobacco smoke. Based on recent evidence, prolonged exposure to some constituents of e-cig aerosols might result in respiratory complications such as asthma, chronic obstructive pulmonary disease and inflammation. Future studies are warranted that focus on establishing correlations between e-cig types, generations and e-liquid flavours and immunological and toxicological profiles to broaden our understanding about the effects of vaping.

\section{Introduction}

While the concept of battery-powered nicotine delivery devices dates to 1963, it took four decades to create such devices. They were first designed by Hon Lik in China in 2003 [1] and were introduced to the United States market in 2007. Since then, these devices have been extremely popular, exhibiting

Received: Aug 232017 | Accepted after revision: Dec 132017

Support statement: This work was supported by a Young Clinical Scientist Award from the Flight Attendant Medical Research Institute (FAMRI; 123253_YCSA_Faculty); National Institutes of Health R15 (7 R15 ES023151 02); a Southern University Foundation Grant (FY2017-017); and a Louisiana Biomedical Research Network Startup Grant (2P20GM103424-14 Subaward No. 100011) to S. Batra. Funding information for this article has been deposited with the Crossref Funder Registry.

Conflict of interest: None declared.

Provenance: Submitted article, peer reviewed.

Copyright OERS 2018. ERR articles are open access and distributed under the terms of the Creative Commons Attribution Non-Commercial Licence 4.0. 
exponential growth in 2013 that resulted in sales of USD 1.7 billion [2]. E-cigs have been marketed as an alternative to cigarette smoking; however, a poll of 5679 Americans conducted by Reuters [3] showed that $75 \%$ of vapers continued to use traditional cigarettes as well. In addition, this survey poll concluded that $10 \%$ of American adults use e-cigs, which is almost four times higher than the USA government 2013 estimate of $2.5 \%$. The other reason for concern is that e-cigs are gaining popularity among youths and nonsmokers. Between 2011 and 2012 there was a two-fold increase in teenage use of e-cigs, with an estimated 1.78 million middle-school and high-school users; indicating that e-cigs may be an urgent public health issue for children that should be addressed [4]. Manufacturers of e-cigs claim that their products are nontoxic, but multiple adverse effects including pneumonia, wheezing and coughing have been associated with them [5]. Ill-effects due to inhaled smoke from traditional tobacco cigarettes are widely known [5-7]. It has been documented that inhalation of tobacco smoke over a prolonged period causes respiratory complications including asthma, chronic obstructive pulmonary disease (COPD), inflammation and related complications [7-9]. However, not much is known about the effects of e-cigs. Recent findings by the United States Food and Drug Administration (US FDA) have shown that the vapours from e-cigs contains some of the same toxic chemicals found in traditional cigarettes [10]. Furthermore, the vapours derived from e-cigs accumulate in the airway epithelium in a similar fashion as the smoke from traditional cigarettes [11]. Considering this evidence, it is necessary that e-cigs be placed under strict scrutiny and that their physiological effects be explored in humans. The current review highlights the knowledge about e-cigs and enumerates some of the concerns associated with the widespread use of these products.

\section{Materials and methods}

To compile this systematic review, a rigorous approach was followed ensuring that all the possible research in public databases (PubMed, BioMed Central, US FDA, Centers for Disease Control and Prevention, the JAMA network and the Agency for Toxic Substances and Disease Registry) was searched with the keywords: "e-cigarettes", "immune effects of e-cigs", "toxicants in e-liquids", "chemical constituents in cigarettes/e-cigarette aerosol/e-liquids", "e-cigarette case reports", "passive vaping”, etc. We found 2300 results for the general search regarding e-cigarettes. Due to the paucity of literature on the toxicological and immunological effects of e-cigs, other keywords provided 200 search hits. We included information from published articles, case reports and conference papers from the period 1980-2017 in this review.

\section{TABLE 1 Four generations of e-cigarettes}

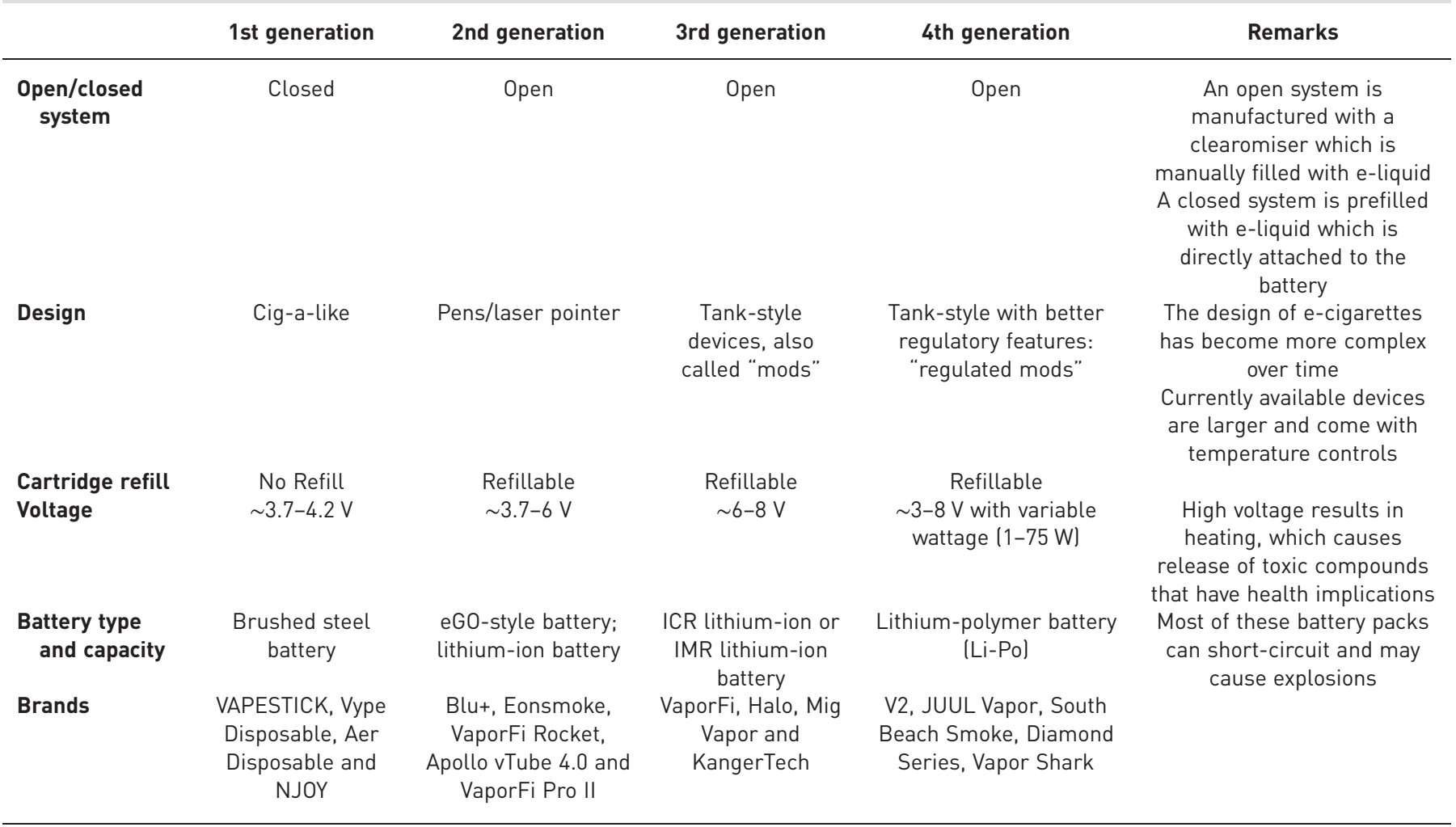

ICR: LiCoO 2 cathode; IMR: $\mathrm{LiMn}_{2} \mathrm{O}_{4}$ cathode. 
Studies published in languages other than English and material from reports with duplicate information/ references were excluded. In total, 104 articles are cited in this review, of which 56 articles focus on evaluating the clinical, immunological and toxicological effects of e-cig vapours, aerosols and liquids, chemical content of e-cig vapours and aerosols, reports on adverse events and human and animal studies, along with current e-cig policies and recommendations. In addition, we selected 48 studies to evaluate the immunological, toxicological and chemical composition of conventional cigarettes that may not have been specifically evaluated, but are related to e-cigs.

\section{Product engineering of e-cigarette devices}

A variety of e-cig device models have emerged over the years; however, the basic design remains the same, consisting of an atomiser, a reservoir containing e-liquid and a rechargeable lithium battery. An overview of the different types of e-cig devices currently available is provided in table 1 [12] and figure 1.

Numerous brands and product designs are available, ranging from simple single-run disposables to highly sophisticated tank-style refillable models. They are engineered to provide automated or manual aerosol formation on inhalation. While the advanced designs and varieties of the vaping devices on the market might be quite an attraction for potential buyers, it makes research in this area an extremely complicated task. Variable voltage, current and temperature from each device may affect the composition of aerosols produced upon inhaling the same e-liquid. Furthermore, the aerosol density of the e-vapours and vaping behaviour and inhalation pattern of the user all might vary and have different toxicological outcomes in humans [13]. Considering this, TRTCHOUnian et al. [14] compared the smoking properties of conventional cigarettes and e-cigs, such as the vacuum required to produce smoke or aerosol and smoke/aerosol density. It was observed that e-cigs require more suction to release aerosols compared to conventional cigarettes. What this means is that the density of aerosol produced by an e-cig declines during smoking because greater pressure needs to be applied by the user to sustain density, thereby sending nonuniform doses of aerosol to the lung tissue. The health implications of this property has not been explored completely, but it is speculated that stronger puffs may cause the aerosols to reach deeper tissues of the lungs, which might have adverse health outcomes in the users.

In another study, Williams and ТАLBOT [15] reported the differences in smoking performance across various brands of e-cigs. In fact, performance (airflow rate required to produce aerosol, pressure drop across e-cigs, aerosol density, etc.) varied between devices of the same model within a brand, which is suggestive of poor quality control during the manufacturing of these devices. Such reports make it evident that the study of the toxicological effects of e-cigs is not as straightforward as that concerning regular cigarettes, and careful design of experiments and interpretation is necessary to get logical answers.

\section{Toxicological profile of e-liquids and e-cig aerosols}

A major concern associated with the use of e-cigs is the lack of knowledge about their constituents. Although the amounts of harmful chemicals found in e-cig aerosols are far lower than conventional cigarettes (table 2), individual exposure depends on many factors such as device voltage, temperature, e-liquid flavour, nicotine content and smoking behaviour of the vaper. Due to the variable nature of all these factors, it is hard to deduce much from the currently available toxicological data related to e-liquids and e-cig aerosols.

While demonstrating the health impacts of acute exposure to e-liquid aerosols, Flouris et al. [16] found that the serum cotinine levels generated by both active and passive smokers was comparable to those generated upon exposure to conventional cigarette smoke. Cotinine is a metabolite of tobacco and a biomarker for tobacco exposure in humans. Comparable levels of cotinine among both the study groups

a)

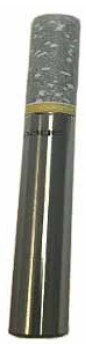

b)

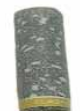

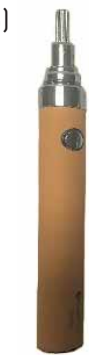

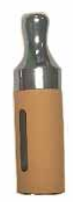

c)

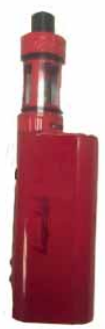

d)

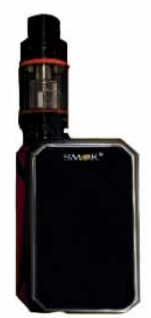

FIGURE 1 E-cigarette models. a) First generation; b) second generation; c) third generation; d) fourth generation. 
TABLE 2 Chemical constituents of e-liquid and e-cigarette aerosols

\begin{tabular}{|c|c|c|c|c|c|}
\hline & $\begin{array}{l}\text { Amount in e-liquids/ } \\
\text { e-cigarette aerosol }\end{array}$ & $\begin{array}{l}\text { Amount in conventional } \\
\text { tobacco cigarette }\end{array}$ & Permissible limit & Toxic effect & $\begin{array}{l}\text { Molecular mechanism of } \\
\text { toxicity }\end{array}$ \\
\hline Acetaldehyde & $\begin{array}{c}0.10-15.63 \mathrm{mg} \cdot \mathrm{L}^{-1} \text { (refill } \\
\text { solution) }[68] \text { or } \\
2.0 \pm 0.1-13.6 \pm 2.1 \mu \mathrm{g} \text { per } \\
150 \text { puffs }[69]\end{array}$ & $\begin{array}{l}680 \mu \mathrm{g} \text { per } \\
\text { cigarette [70] }\end{array}$ & $\begin{array}{c}45-270 \mathrm{ppm} \text { for } 1 \mathrm{~h} \text { (AEGL } \\
\text { and NAC) [71] }\end{array}$ & $\begin{array}{l}\text { Eye, skin and respiratory tract } \\
\text { irritation on acute exposure } \\
\text { Coughing, erythema, } \\
\text { pulmonary oedema and } \\
\text { necrosis on higher exposures } \\
\text { Probable carcinogen based } \\
\text { on animal and human cancer } \\
\text { studies }[72,73]\end{array}$ & $\begin{array}{l}\text { Readily binds to protein and } \\
\text { DNA, forming damaging } \\
\text { adducts and impairing normal } \\
\text { function and enzyme activity } \\
{[74,75]}\end{array}$ \\
\hline Acetone & $\begin{array}{c}2.9 \mathrm{mg} \cdot \mathrm{m}^{-3}[76] \text { or } \\
0.16 \mathrm{ppm} \text { per } \\
38-\mathrm{mL} \text { puff [77] }\end{array}$ & $\begin{array}{l}287 \mu \mathrm{g} \text { per } \\
\text { cigarette [70] }\end{array}$ & $\begin{array}{l}750-1000 \text { ppm per } 8-h \\
\text { work shift as per OSHA } \\
\text { guidelines [78] }\end{array}$ & $\begin{array}{l}\text { Respiratory irritant in small } \\
\text { quantities; nausea, CNS } \\
\text { depression and } \\
\text { cardiorespiratory failure in } \\
\text { large amounts }[78,79]\end{array}$ & $\begin{array}{l}\text { Metabolism in high amounts } \\
\text { is not possible, leading to its } \\
\text { accumulation and toxicity [78] }\end{array}$ \\
\hline Acrolein & $\begin{array}{l}\text { ND to } 41.9 \pm 3.4 \mu \mathrm{gg} \text { per } \\
150 \text { puffs [69] }\end{array}$ & $\begin{array}{c}60-140 \mu \mathrm{g} \text { per } \\
\text { cigarette }[70,80]\end{array}$ & $\begin{array}{l}0.1 \mathrm{ppm} \text { per } 8 \mathrm{~h} \text { as per } \\
\text { OSHA guidelines [81] }\end{array}$ & $\begin{array}{c}\text { Highly toxic even in small } \\
\text { quantities } \\
\text { Respiratory and } \\
\text { cardiovascular toxicant } \\
\text { Possible carcinogen }[79,81]\end{array}$ & $\begin{array}{l}\text { Highly reactive, leading to } \\
\text { DNA and protein adduction, } \\
\text { endoplasmic reticulum stress, } \\
\text { membrane damage, } \\
\text { mitochondrial disruption, } \\
\text { oxidative stress and immune } \\
\text { dysfunction [82] }\end{array}$ \\
\hline Cadmium & ND & $\begin{array}{l}0.103 \mu \mathrm{g} \text { per } \\
\text { cigarette [70] }\end{array}$ & $\begin{array}{l}5 \mu \mathrm{g} \cdot \mathrm{m}^{-3} \text { of air for } 8 \mathrm{~h} \text { as } \\
\text { per OSHA guidelines [83] }\end{array}$ & $\begin{array}{l}\text { Chronic inhalation causes } \\
\text { pulmonary changes with } \\
\text { obstructive damage } \\
\text { Toxicity leads to renal } \\
\text { dysfunction } \\
\text { Associated with teratogenicity } \\
\text { in animals, but limited data on } \\
\text { humans }[84,85] \\
\text { Classified as a carcinogen, } \\
\text { showing association with lung } \\
\text { and prostate cancers [86] }\end{array}$ & $\begin{array}{l}\text { Has a long biological half-life } \\
\text { ( } 15-20 \text { years) } \\
\text { Interacts with DNA } \\
\text { repair machinery, acts as a } \\
\text { catalyst for ROS production, } \\
\text { increases lipid peroxidation } \\
\text { and induces apoptosis in } \\
\text { cellular systems [87, 88] }\end{array}$ \\
\hline Chromium (Cr) & $0.007 \mu \mathrm{g}$ per 10 puffs [28] & $\begin{array}{c}0.0042 \mu \mathrm{g} \text { per } \\
\text { cigarette [70] }\end{array}$ & $5 \mu \mathrm{g} \cdot \mathrm{m}^{-3}$ of air [89] & $\begin{array}{c}\text { Acute exposure causes fever, } \\
\text { nausea, vomiting, diarrhoea; } \\
\text { chronic exposures may cause } \\
\text { irritation, nasal ulcers and } \\
\text { perforations } \\
\text { Lung cancer is a major } \\
\text { long-term effect }[70,79]\end{array}$ & $\begin{array}{l}\text { Most of the toxicity is } \\
\text { attributable to chromium(IV). } \\
\text { Chromium(IV) is readily } \\
\text { soluble and under } \\
\text { physiological conditions, can } \\
\text { produce reactive } \\
\text { intermediates, hydrogen } \\
\text { peroxide and GSH, which can } \\
\text { attack DNA, protein and } \\
\text { membrane lipids [90] }\end{array}$ \\
\hline
\end{tabular}


TABLE 2 Continued

\begin{tabular}{|c|c|c|c|c|c|}
\hline & $\begin{array}{l}\text { Amount in e-liquids/ } \\
\text { e-cigarette aerosol }\end{array}$ & $\begin{array}{l}\text { Amount in conventional } \\
\text { tobacco cigarette }\end{array}$ & Permissible limit & Toxic effect & $\begin{array}{l}\text { Molecular mechanism of } \\
\text { toxicity }\end{array}$ \\
\hline Formaldehyde & $\begin{array}{c}0.02-10.09 \mathrm{mg} \cdot \mathrm{L}^{-1} \text { refill } \\
\text { solution }[68] \text { or } \\
3.2 \pm 0.8-56.1 \pm 1.4 \mu \mathrm{g} \text { per } \\
150 \text { puffs }[69]\end{array}$ & $\begin{array}{c}20-100 \mu \mathrm{g} \text { per } \\
\text { cigarette }[70,80]\end{array}$ & $\begin{array}{c}0.75 \text { ppm per 8-h work } \\
\text { shift as per OSHA } \\
\text { guidelines [91] }\end{array}$ & $\begin{array}{l}\text { Potent respiratory stimulant } \\
\text { causing irritation, cough, } \\
\text { wheezing, significant } \\
\text { respiratory inflammation, } \\
\text { pneumonia and bronchitis on } \\
\text { exposure } \\
\text { Has been recognised as a } \\
\text { carcinogen } \\
\text { Has more toxic effects on } \\
\text { children compared to adults } \\
\text { Known to cause neurological } \\
\text { symptoms upon high-level } \\
\text { exposure }[70,79,91]\end{array}$ & $\begin{array}{l}\text { Highly reactive electrophilic } \\
\text { reagent that can easily attach } \\
\text { to neutrophilic biological } \\
\text { targets, leading to formation of } \\
\text { harmful adducts and ROS [92] }\end{array}$ \\
\hline Nicotine & $\begin{array}{l}0-87.2 \mathrm{mg} \cdot \mathrm{mL}^{-1} \text { refill } \\
\text { solution or } \\
0.3 \pm 0.2-8.7 \pm 1.0 \mathrm{mg} \text { per } \\
150 \text { puffs }[93]\end{array}$ & $\begin{array}{l}1.0-1.5 \mathrm{mg} \text { per } \\
\text { cigarette [80] }\end{array}$ & $0.5 \mathrm{mg} \cdot \mathrm{m}^{-3} \mathrm{skin}[94]$ & $\begin{array}{l}\text { Nausea, vomiting, increased } \\
\text { salivation, bronchorrhea, } \\
\text { hyperpnoea, hypertension, } \\
\text { tachycardia, vasoconstriction, } \\
\text { headache, restlessness, etc. } \\
\text { Causes developmental } \\
\text { defects } \\
\text { Addictive }[94,95]\end{array}$ & $\begin{array}{l}\text { Mechanism not fully } \\
\text { understood, but toxicity } \\
\text { attributed to oxidative damage, } \\
\text { lipid peroxidation and DNA } \\
\text { adduct formation [96] }\end{array}$ \\
\hline $\mathrm{N}$-Nitrosamines & $\begin{array}{l}\text { ND to } 28 \mu \mathrm{g} \text { per } \\
150 \text { puffs [69] }\end{array}$ & $\begin{array}{l}0.019-72 \mu \mathrm{g} \text { per } \\
\text { cigarette [70] }\end{array}$ & $0.3 \mathrm{ng} \cdot \mathrm{m}^{-3}[97]$ & Carcinogen [70] & $\begin{array}{c}\text { Forms diazonium or oxynium } \\
\text { ions which cause alkylating } \\
\text { DNA } \\
\text { Activates various oxidative } \\
\text { damage and radical } \\
\text { scavenging pathways [98] }\end{array}$ \\
\hline Toluene & $\begin{array}{c}\text { ND to } 6.3 \pm 1.5 \mu \mathrm{g} \text { per } \\
150 \text { puffs [69] }\end{array}$ & $\begin{array}{l}72.8 \mu \mathrm{g} \text { per } \\
\text { cigarette [70] }\end{array}$ & $\begin{array}{c}200 \text { ppm (300-500 ppm for } \\
\text { a maximum } 10 \text { min per } \\
\text { 8-h shift, as per OSHA } \\
\text { guidelines) [99] }\end{array}$ & $\begin{array}{c}\text { Neurotoxicity including } \\
\text { headache, nausea, euphoria, } \\
\text { depression, cognitive } \\
\text { impairment, etc. [100] }\end{array}$ & $\begin{array}{l}\text { Rapidly absorbed, has high } \\
\text { affinity for lipids and crosses } \\
\text { the blood-brain barrier } \\
\text { Metabolises to form } \\
\text { hippurate ions resulting in } \\
\text { metabolic acidosis and } \\
\text { hypokalaemia } \\
\text { Has been found responsible } \\
\text { for increased production of } \\
\text { dopamine [101] }\end{array}$ \\
\hline Lead & $\begin{array}{l}0.03 \pm 0.03-0.57 \pm 0.28 \mu \mathrm{g} \\
\text { per } 150 \text { puffs }[69]\end{array}$ & $\begin{array}{r}0.00128 \mu \mathrm{g} \text { per } \\
\text { cigarette [70] }\end{array}$ & $\begin{array}{c}50 \mu \mathrm{g} \cdot \mathrm{m}^{-3} \text { per } 8 \mathrm{~h} \\
\text { (NIOSH) [102] }\end{array}$ & $\begin{array}{l}\text { Neurotoxin, cardiotoxin, } \\
\text { behavioural changes and } \\
\text { developmental changes [103] }\end{array}$ & $\begin{array}{l}\text { Causes oxidative stress and } \\
\text { ionic imbalance [104] }\end{array}$ \\
\hline
\end{tabular}

AEGL: acute exposure guideline level; NAC: National Advisory Committee; OSHA: Occupational Safety and Health Administration; CNS: central nervous system; ND: not determined; ROS: reactive oxygen species; GSH: glutathione; NIOSH: National Institute for Occupational Safety and Health. 
thus means that e-cigs are no different to regular cigarettes as far as the health risks are concerned. Elaborating on the toxic effects of nicotine present in e-cig aerosols in particular, Farsalinos et al. [17] reported that plasma nicotine levels of healthy e-cig users increased by $35-72 \%$ due to the use of new-generation e-cig devices, compared to first-generation devices. In addition, a literature review by SCHROEDER and Hoffman [18] concluded that the nicotine exposure upon use of e-cigs depends on product experience and the usage behaviour of the vaper. They found that experienced e-cig users could achieve nicotine concentrations comparable to those achieved by conventional cigarette smokers. In fact, while highlighting the addictive properties of e-cigs, Foulds et al. [19] showed that long-term e-cig users have high e-cig dependence scores.

Another group of researchers tested 13 kinds of commercially available e-liquids and found the presence of acetaldehyde and formaldehyde in eight of the tested samples [20]. The International Agency for Research on Cancer has classified formaldehyde and acetaldehyde as human carcinogens in groups 1 and 2B, respectively, which should be a reason for concern [21]. VARLET et al. [22] analysed 42 models of refill liquids for e-cigs from 14 different brands to assess their toxicity. High amounts of $\alpha$ - and $\beta$-pinene, $\gamma$-terpinene and benzene 1-methyl-4-(1-methylethyl) (para-cymene), used to enhance their flavours, were detected in several products. In addition, 2,3-butanedione, a diketone associated with respiratory diseases, was detected in three samples, with concentrations in one sample exceeding the recommended National Institute of Occupational Safety and Health safety limits. Moreover, none of the samples analysed in this study were found to be completely free of potentially toxic compounds. However, these studies only tested the chemical constituents of e-liquids and did not consider their combustion products, which could be even more harmful considering the reactive nature of such carbonyl compounds. These shortcomings were overcome in a recent study conducted by JENSEN et al. [23], which used nuclear magnetic resonance to identify the products in e-cig aerosols. This study identified glycidol (carcinogen), vinyl alcohol isomers and dihydroxyacetone (associated with inhalation hazards) in e-cig aerosols and concluded that further investigation is required to define the association between illness and the composition of e-cig aerosols. Furthermore, this group also concluded that variations caused by thermal oxidation, acid/metal-based catalysis of propylene glycol and glycerol and heat transfer efficiencies of the vaping devices should be considered in the design of future studies to eliminate experimental inconsistencies. Overall future toxicological studies need to assess specifically the level of combustible by-products of the carbonyl compounds present in e-liquids as they could be responsible for the formation of reactive oxygen species in the exposed tissues and cause oxidative damage in lungs.

One of the unique selling point of e-cigs is the wide variety of flavours. According to a 2014 report, e-liquids exist in 7764 unique flavours sold under 466 brands [13]; however, these flavouring agents could also lead to toxicity. A study based on determining the cytotoxicity of e-liquids in human embryonic stem cells and in mouse neural stem cells demonstrated its direct correlation with the concentration of flavouring additives [24]. Diacetyl, an artificial butter flavouring found in some flavoured e-liquids, has been associated with a rare and severe lung condition, bronchiolitis obliterans, commonly known as "popcorn lung" [8]. An animal study conducted by MorGan et al. [25] found compromised respiratory epithelium in mice exposed to heated diacetyl vapours. In 2012, BAHL et al. [24] compared the cytotoxicity of various flavours and identified Ceylon cinnamon as the most toxic of the 36 flavourings tested on human embryonic stem cells. Another study demonstrated that flavouring additives containing diacetyl and 2,3-pentanedione cause a reduction in sodium transport in normal human bronchial/tracheal epithelial cells without affecting sodium-potassium pump activity or chloride ion transport [26]. Similarly, 2,5-dimethypyrazine, found in vanillin and chocolate flavourings, was shown to cause alterations in the ion conductance in primary mouse tracheal epithelial cells. Mechanistic evaluation confirmed that the increase in ion conductance evoked by 2,5-dimethylpyrazine was caused due to a protein kinase A-dependent activation of the cystic fibrosis transmembrane conductance regulator ion channel [27].

In a study conducted by Williams et al. [28], the aerosols of e-cigs were demonstrated to have high concentrations of silver, iron, nickel, aluminium and silicate and nanoparticles $(<100 \mathrm{~nm})$ of tin, chromium and nickel. Moreover, it was shown that titanium dioxide nanoparticles released in e-cig aerosols impair DNA repair by causing single-strand breaks and oxidative lesions to DNA in A549 cells [29]. These heavy metals could be released by the heating element and could pose serious health implications in users. Advocates of e-cigs believe that aerosols from e-cigs contain only "water vapour"; however, evidence contradicts this. ZHANG et al. [30] employed a human deposition model to study the likely deposition of e-liquid aerosol on vaping both propylene glycol- and vegetable glycerin-based e-liquids. In the single-puff experiments performed during this study, both solvents produced comparable sizes of aerosol particles. Interestingly, the study model estimated that $\sim 20-27 \%$ of particles from aerosols could be deposited in the circulatory system and other organs, which is comparable to the $25-35 \%$ deposition rate for conventional cigarettes. Along these lines, a recent study conducted by 
MiкheEv et al. [31] measured the particle size distribution of e-cig aerosols using advanced real-time instrumentation. They found that the aerosol size distribution generated by e-cigs is considerably different from that produced by tobacco smoke and exhibits a bimodal distribution of particles ranging from the nanoparticle (in high numbers) to submicron size range. Metals such as lead, chromium and nickel (present at $\sim 2-100$ times higher than in tobacco cigarettes) were found to be responsible for the nanoparticle formation. The study concluded that these e-cig aerosols could have toxicological implications, and, owing to the small size of particles, may affect sensitive sites including the lungs, bone marrow, spleen, heart and even the central nervous system.

Overall, the toxicological studies conducted thus far show some concerning results and point towards probable ill-effects of e-cigs on the general population. However, various shortcomings in study design render the outcomes inconclusive. Many of the toxicological analyses are performed on e-liquids, which are not the inhaled product of vaping and thus they do not provide the complete picture. The chemicals released on vaping depends on multiple variable factors such as the type of device used, the flavour of the e-liquid and its composition, and the smoking behaviour of the vaper. It is impossible to simulate all these conditions for toxicity testing. Furthermore, very few in vivo studies have been conducted to test the long-term effect of e-cig aerosols in mammals. In future, well-designed research models and experimental plans will be required to deduce the toxicological impact of e-cigs on short-term and long-term users.

\section{Immunological effects of e-cig use}

The adverse health effects of conventional cigarette smoking are well known; however, the immunological responses to e-liquid vaping remain elusive. Few reports have been published, but the results seem to be contradictory. A study comparing the effects of e-cigs and traditional cigarettes on pulmonary function and nitric oxide release in exhaled air of smokers versus nonsmokers found that short-term use of e-cigs did not lead to any adverse health effects in nonsmokers [32]. In addition, Misra et al. [33] found no evidence of genotoxicity, cytotoxicity or adverse inflammatory responses caused by e-liquids in human alveolar epithelial cells (A549). Moreover, as per this report, varying the nicotine content of the e-liquids caused no significant effect on interleukin (IL)-8 production, cytotoxicity or mutagenicity of A549 cells. These findings led the authors to conclude that the presence of nicotine in e-liquids does not affect mutagenicity in in vitro study models. However, the downside of these findings was that this was an in vitro study employing direct treatment of human alveolar epithelial cells with e-liquids or pad-collected aerosols, and thus the model did not completely mimic in vivo exposure conditions. Use of a puffing system to expose the cells or animals to e-vapours would be a more effective means of studying the real-life scenario. In contrast, exposure of human umbilical cord vein endothelial cells to e-cig aerosols from 11 different e-liquid flavours revealed a concentration-dependent and temporal increase in cell death in response to exposure to five of the flavours tested. Moreover, the highly toxic e-liquids were found to contain flavouring agents from plant extracts [34]. Cervellati et al. [35] reported that exposure to e-cig vapours (balsamic flavour with and without nicotine) induces the production of pro-inflammatory cytokines and chemokines (such as IL-1 receptor- $\alpha$, IL-8, IL-10, granulocyte colony-stimulating factor, interferon- $\gamma$, RANTES, tumour necrosis factor (TNF)- $\alpha$ and vascular endothelial growth factor) by human alveolar epithelial cells (A549) and keratinocytes (HaCaT cells). Furthermore, in a recent study, e-cig vapour extracts were reported to induce the expression of $\mathrm{CD} 11 \mathrm{~b}$ and $\mathrm{CD} 66 \mathrm{~b}$ in neutrophils isolated from peripheral blood of healthy nonsmokers, which play a critical role in their adhesion and migration to the site of inflammation. In addition, e-cig vapour extract induces neutrophil elastase and matrix metalloproteinase- 9 release by neutrophils, which may cause tissue destruction leading to the development of emphysematous lung tissue in patients with COPD. This study also reported a subsequent increase in p38 mitogen-activated protein kinase activation (figure 2). The observed effects were dose-dependent and in accordance with the findings from smoke-exposed models [36].

In 2014, Wu et al. [37] conducted a study to demonstrate the role of e-liquids in inducing inflammatory responses and regulating innate defence in primary airway epithelial cells. It was observed that nicotine-free e-liquid induced IL-6 production and promoted human rhinovirus (HRV) infection in human primary airway epithelial cells from nonsmokers. It was found that the observed effects were amplified by the presence of nicotine. In contrast, the expression of the host-defence molecule SPLUNC1 (short palate, lung and nasal epithelium clone 1) was abrogated in human airway epithelial cells following treatment with nicotine-free e-liquid. Additionally, it was observed that SPLUNC-1 deficiency significantly increased HRV burden in the lungs of $\mathrm{C} 57 \mathrm{Bl} / 6$ mice (figure 2). This study indicates that exposure to e-liquids can lead to an immune-compromised state and an increase in susceptibility to microbial infection. Sussan et al. [38] reported that 2 weeks' exposure of C57BL/6 mice to e-cig vapours causes impairment of pulmonary viral and bacterial clearance. Furthermore, researchers observed that exposure to e-cig vapours results in increased virulence of methicillin-resistant Staphylococcus aureus and concluded that e-liquids can boost drug resistance in bacteria by promoting biofilm formation and causing alterations 


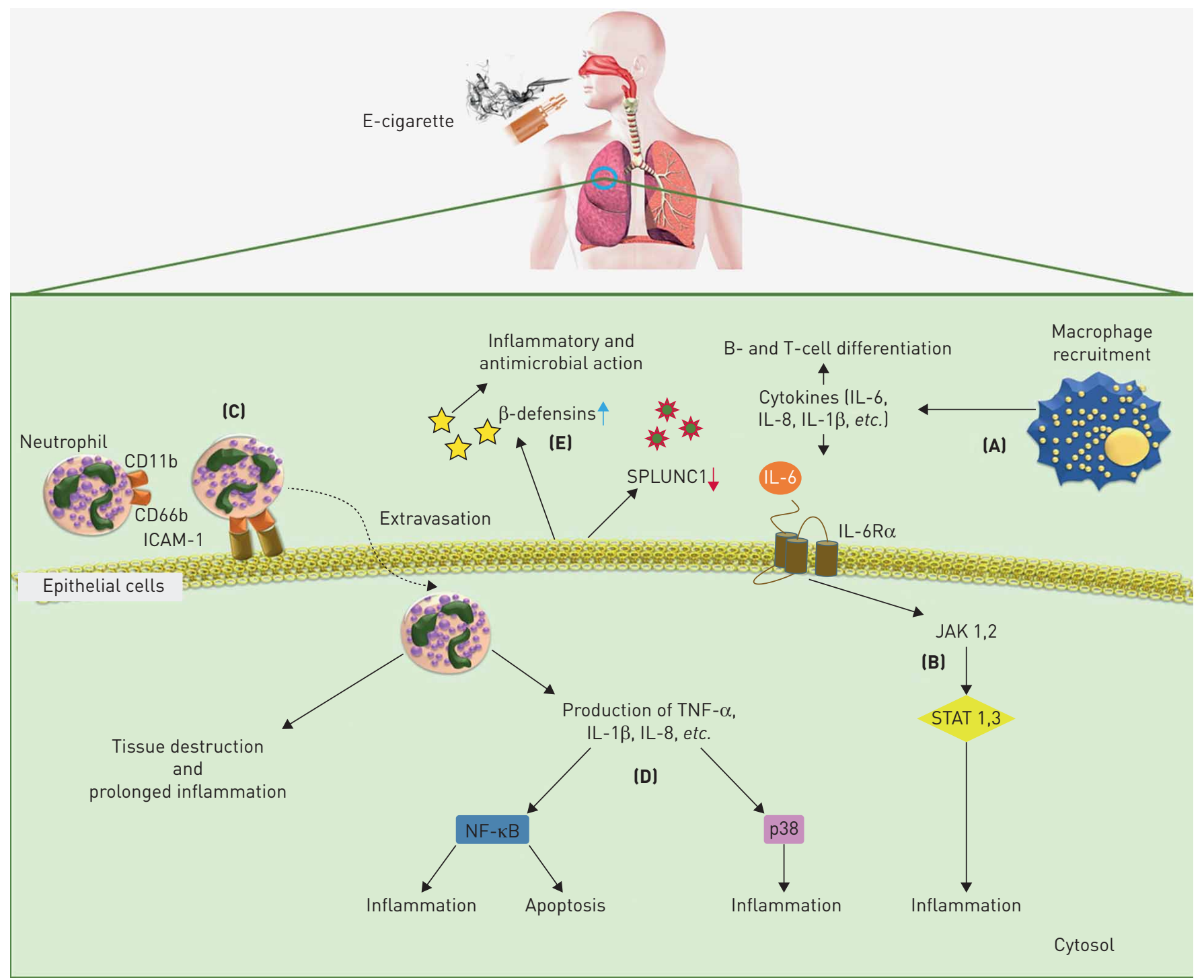

FIGURE 2 Inflammatory responses elicited by e-liquid vaping. E-liquid vaping results in recruitment of immune cells to the site of exposure, i.e. nasal and throat epithelial cells. Tissue macrophages are among the first lines of defence activated by exposure to e-cigarette vapours. Activated macrophages participate in phagocytosis and release pro-inflammatory cytokines such as interleukin (IL)-6, IL-10, IL-1 $\beta$, etc. a) In turn, these cytokines lead to B-cell and T-cell differentiation and participate in downstream signalling mechanisms. b) IL-6 mediated activation of the JAKSTAT (Janus tyrosine kinase/signal transducer and activator of transcription) pathway is one such downstream pathway that is known to be activated by the action of e-vapours. IL-6 production by exposure to e-vapours causes STAT3 phosphorylation which further elicits production of other cytokines and chemokines, and, most importantly promotes neutrophil adhesion and migration into the lungs. c) Neutrophil migration into the tissue results in release of neutrophil elastase and matrix metallopeptidase-9, which in turn causes tissue destruction in emphysematous lungs and chronic obstructive pulmonary disease. d) Furthermore, neutrophils release various cytokines and chemokines such as tumour necrosis factor (TNF)- $\alpha, \mathrm{IL}-10$ and IL-1 $\beta$, which activate p38 and nuclear factor (NF)-кB mediated signalling pathways that might result in inflammation or apoptosis. e) Exposure to e-vapours further results in release of $\beta$-defensins by epithelial cells. $\beta$-defensins have antimicrobial actions and participate in eliciting an inflammatory response; however, production of the SPLUNC1 (short palate, lung and nasal epithelium clone 1) protein known to induce innate immunity in airway epithelial cells is lowered on exposure to e-vapours. ICAM: intercellular adhesion molecule.

in surface charge [39]. Such studies, though preliminary, present a newer and graver problem of increased bacterial infection and drug resistance due to increased use of e-cigs.

Transcriptome sequencing of human bronchial epithelial cells following exposure to e-cig vapours and traditional cigarette smoke demonstrated the induction of distinct gene expression profiles. The results demonstrate that compared to tobacco smoke, the use of e-vapours elicits subdued cellular toxic responses. However, e-vapours were reported to cause a significant enrichment in the expression of genes associated with phospholipid and fatty acyl triacylglycerol metabolism, which remained unaffected in traditional smoke-treated samples. Since e-liquids are enriched in glycerin and phosphatidate, the upregulation of the glycerophospholipid biosynthetic pathway is not surprising. Nevertheless, it would be interesting to further 
explore the consequences of such upregulation as it may have effects on the formation of membrane microdomains (lipid rafts) leading to altered signalling. It was observed in the same study that exposure of human bronchial epithelial cells to e-vapours resulted in the significant upregulation of DEFB1 and DEFB4, genes associated with the $\beta$-defensins pathway (figure 2). $\beta$-defensins are antimicrobial peptides expressed during inflammation, and interestingly, the expression of these genes was further induced in response to challenge with nicotine-containing e-vapours [40]. Although the readouts from this study did not reveal alarmingly harmful effects from human use of e-cigs, it certainly raised concerns over the health issues that may arise from the long-term use of such devices. Furthermore, a group of researchers from Boston University (Boston, MA, USA) suggested that exposure to e-vapours might increase the risk of lung cancer. Their findings using immortalised human bronchial epithelial cells (SV40) exposed to e-cig vapours showed a similar pattern of gene expression as tobacco smoke-exposed cultures [41]. A recent study was conducted to determine the effect of whole-body exposure of male Sprague Dawley rats to e-cig aerosols for 11 cycles-day ${ }^{-1}$ of 17 -s puffs for five consecutive days per week for 4 weeks. The study reported that e-cig exposure has a booster effect on the expression of phase 1 carcinogen-bioactivating enzymes in the lungs of exposed animals. Furthermore, both free radical production in the lungs and oxidation-induced DNA damage in peripheral blood were increased. These findings suggest that there is a significant increase in DNA mutations and cancer-causing changes in rats exposed to e-cig aerosols under experimental conditions [42]. However, studies demonstrating the effects of e-cigs are exploratory at present and further investigations will be required to prove the carcinogenicity of e-vapours.

While these reports certainly point towards harmful health effects of e-liquids, examining their impact on inflammatory responses is highly challenging due to the wide variety of flavours, which themselves may pose substantial threats to human health. The limitations of currently published work include the use of small sample sizes, which does not provide true understanding about the health impact of e-cig use on human cells. Substantial use of in vitro model systems without much in vivo replication or clinical evidence is another matter of concern. Most of these studies can only be extrapolated to understand the responses by electronic nicotine delivery systems (ENDS) users with no former history of smoking. It should be noted that most e-cig users also smoke traditional cigarettes, which increases the complexity of their responses. Thus, the marketing and popularisation of these products to alleviate tobacco addiction makes it necessary to extend studies to include populations or groups with compromised immune systems. A detailed understanding of the ill-effects of e-cig use including mutagenicity, carcinogenicity and effects on growth and reproductive health of an individual needs to be gained [43-45].

\section{Vaping: is it safe for health?}

Currently, there is limited understanding of the full health impacts of e-cig usage, and only scant reports associating e-cig use with cardiovascular, gastrointestinal and neurological risks are available. A study conducted by Monroy et al. [46] suggests that the use of e-cigs containing nicotine may have a damaging effect on heart cells, as acute e-cig use was found to affect left ventricular function and cause a delay in myocardial relaxation in a 70-year-old female. In addition, there have been other reports of pulmonary atrial fibrillation and acute myocardial infarction in e-cigs users, suggesting that e-cig use might pose a risk to the cardiovascular system [47]. There are case reports involving diagnosis of relapsed ulcerative colitis and enterocolitis in developing infants in association with e-cig aerosol exposure [48].

Compared to other associated health risks, it is more apparent that there are considerable pulmonary health risks associated with continued e-cig usage. To this end, VARDAVAS et al. [49] reported an increase in total respiratory impedance and flow respiratory resistance, in addition to a significant decline in exhaled nitric oxide fraction $\left(F_{\mathrm{eNO}}\right)$ levels, a marker for eosinophilic inflammation on short-term exposure ( $a \mathrm{~d}$ lib for $5 \mathrm{~min}$ ) of 30 healthy individuals aged 19-56 years to e-cig vapours. On the downside, this study did not include a treatment group of individuals smoking conventional cigarettes only, making it hard to compare the safety of e-cigs with tobacco cigarettes. FeNO is a biomarker for lung inflammation, which is affected by multiple factors including duration of exposure, smoking habits and current medication of the user [50]. Thus, it is difficult to predict probable decline in lung inflammation due to vaping just by measuring the FeNO levels in the lungs. Furthermore, there are contradictory reports in relation to the FeNO levels on e-vapour exposure. Several studies have reported an increase in FeNO levels [51], while others observed no change [16]. As a part of an online study HUA et al. [5] analysed online forums to gather information about the positive and negative health effects of e-cig use. Most of the symptoms included mouth/throat irritation, dry cough, insomnia, increased palpitation, tightening of the lungs and difficulty breathing. The major disadvantage of this kind of study is that it relies on the individual's assessment of health effects without a proper control or health history. Nevertheless, it still suggests an association between e-cig use and health risks. Overall, the currently available clinical data do not associate serious health risks with e-cig use, but it should be noted that the current studies have not assessed the long-term effects of e-cig use and lack the proper study design required to gather conclusive outcomes. 


\section{Regulations imposed on the use of e-cigs}

In 2016, the US FDA finalised its regulations concerning ENDS (e-cigs, vape pens, hookah tobacco and pipe tobacco), placing them under the category of tobacco products. The US FDA now regulates the manufacture, import, packaging, labelling, promotion, sales and distribution of ENDS. Moreover, the sale of e-cigs to minors (aged $\leqslant 18$ years) is prohibited and photo-identification is mandatory for the buyers aged $<26$ years [52], and the sale of e-cigs or related products at vending machines (except in adult-only facilities) and free sample distribution for promotions is prohibited by law. Devices introduced after 2007 are required to undergo the same level of US FDA review that applies to conventional cigarettes for safety, warning labels and other restrictions. Under the current regulations, the US FDA will have the authority to review the design, nicotine content, delivery, voltage and formulations of all ENDS and flavoured tobacco products that have not yet been released onto the market. This legislation is intended to result in the evaluation and communication of all e-liquid ingredients and their potential risks $[52,53]$. However, there is recent speculation that a United States House of Representatives bill might weaken the controls imposed by the US FDA and exempt the e-cigs from the tobacco regulations [54], a move that would be welcomed by e-cig manufacturers.

\section{Future directions and conclusions}

Overall, it could be said that our current knowledge about e-cigs and related products is very limited and their growing popularity serves to widen the gap between the impending effects and our lack of information regarding the effects on human health. There are many factors that require streamlining and serious consideration before drawing conclusions in relation to these products.

\section{Manufacturing practices}

This is the area which might help the most but is being talked about the least. Reports suggest that the levels of nicotine and other e-liquid contents vary across brands and flavours, while the labels themselves have been found to be misleading and inaccurate [55]. Researchers at North Dakota State University (Fargo, ND, USA) [56] determined the levels of nicotine in 70 e-liquids containers from 16 unlicensed vape stores and observed that $17 \%$ of the samples contained a higher percentage of nicotine than reported on the labels, with one sample containing a quantity of nicotine $172 \%$ higher than reported. This study clearly illustrates that there needs to be stricter law enforcement and quality checks placed on the manufacture, packaging and sale of these products. Considering their popularity in the global market, these products will probably continue to emerge over time, and regulations with regards to their contents need to be introduced, keeping in mind the general health and safety of users and the exposed population.

\section{Susceptible groups}

While most of the e-cig research so far has focused about the effects on adult vapers, few studies talk about the effects of their use by susceptible groups such as pregnant females, youths, immune-compromised individuals and psychiatric patients. Ever since their introduction, these products have been marketed as being safer and better options than smoking. As a result, these products are gaining popularity among youths and other susceptible groups. In fact, among specific subpopulations of psychiatric and COPD patients who are prone to be smokers, these products are used as smoking cessation tools to improve quality of life. Unfortunately, we do not have much scientific evidence in support of this approach [57]. Similarly, the effect on pregnant females and their growing fetuses has not been studied thoroughly. Increasingly, pregnant smokers switch to e-cigs during pregnancy, hoping that they are safer for their babies. This is due to a failure to provide proper guidance at clinics regarding the use of ENDS and related products. Due to the lack of substantial evidence, it is in the best interest of both mother and child to consider vaping harmful and that proper guidance be given at healthcare facilities in this regard $[58,59]$.

\section{Smoking cessation tool}

Evidence supporting the use of e-cig for smoking cessation is sparse due to the lack of clinical studies [60]. Short-term studies have found that e-cig usage helped to reverse the harm caused by tobacco smoking in a significant number of volunteers who wished to quit smoking tobacco [61, 62]; however, it should be noted that this study did not assess the effect of e-cig use on smoking cessation and relapse over a long period of time. Another study by the same group compared the effectiveness of nicotine-containing e-cigs versus nicotine patches as a smoking cessation tool over a 6-month period. It was a randomised controlled trial consisting of 657 study participants, making this a well-conducted study. The study outcome discussed the challenges of deducing the performance and quality of such products due to the variety of brands and flavours of e-cigs available [63]. E-cigs maintain nicotine dependence, making it harder for smokers to quit $[64,65]$. Unlike traditional cigarettes, there is no set dosage for nicotine delivery with 
e-cigs. Bullen et al. [62] reported a high peak serum nicotine level (1.3 $\mathrm{mg} \cdot \mathrm{mL}^{-1}$ in $\left.19.6 \mathrm{~min}\right)$ following the use of $16 \mathrm{mg}$ nicotine-containing e-cigs as compared to cigarettes (13.4 ng. $\mathrm{mL}^{-1}$ in $14.3 \mathrm{~min}$ ). Moreover, the levels of nicotine in refill solutions are not consistent and can vary from the amounts listed on the package label. Furthermore, since there is no end indicator on the devices that can act as a warning sign, an individual may smoke e-cigs for an extended period and reach blood nicotine levels higher than the levels obtained when smoking conventional cigarettes. In addition, the levels of toxicants present in e-cigs are reportedly much higher than those found in nicotine replacement therapy products [66]. Current intervention studies do not present data on long-term health effects of e-cigs. Proper regulation and improved quality control practices during the manufacturing of these products is essential for their regulated use in future.

\section{Passive vaping}

The available scientific literature regarding the health effects of passive vaping on children and adults is very limited, although initial reports indicate the potential for harm. While assessing indoor air quality after e-cig use, McAuley et al. [67] reported the release of pollutants including volatile organic compounds, carbonyls, nicotine, polycyclic aromatic hydrocarbons and nitrosamines by e-cigs, albeit at levels posing no significant risk to human health. In another study, ScHober et al. [51] studied the indoor air quality released by nine volunteers vaping in a ventilated room for $2 \mathrm{~h}$. They found the presence of 1,2-propanediol, glycerine, nicotine and high concentrations of particulate matter (mean $197 \mu \mathrm{g} \cdot \mathrm{m}^{-3}$ ) in the e-cig emissions. This study proved that e-cig emissions are not smoke-free, as claimed, and can adversely affect indoor air quality. In fact, ultrafine particles of 1,2-propanediol have been known to deposit in human lungs following inhalation causing production of nitric oxide and inflammation. Another study assessing the health impacts of passive vaping concluded that there is an increase in the serum cotinine (metabolite of nicotine inhalation) levels equivalent to that seen following inhalation of tobacco smoke [16]. Together, these findings raise concern over the use of e-cigs in public places, as the risks of exposure of high-risk individuals to e-cig aerosols remains unclear.

In conclusion, a significant number of studies need to be conducted to reveal the full picture of the safety and risks associated with e-cigs and related products. Moreover, future research needs to overcome the shortcomings of currently employed research models. Furthermore, studies published by tobacco companies should be reviewed critically as their presentation could be biased and without inclusion of negative health effects or mention of the limitations of their study models [60]. In addition, a proper standardised vaping system is required for proper execution and analysis of vaping experiments in the laboratory setting, and the long-term effects of e-cigs use need to be studied in detail with equal inclusion of proper control groups. Because most vapers also smoke conventional cigarettes, the combined effects of smoking and vaping need to be emphasised as well. Lastly, it is important to spread awareness about these products among the general population to avoid potential ill-effects in the future.

\section{References}

1 Crotty Alexander L, Fuster M, Montgrain P, et al. The need for more e-cigarette data: a call to action. Am J Respir Crit Care Med 2015; 192: 275-276.

2 Fewer Smokers Believe E-cigarettes Are a Safer Alternative to Cigarettes. www.elsevier.com/about/press-releases/ research-and-journals/fewer-smokers-believe-e-cigarettes-are-a-safer-alternative-to-cigarettes Date last updated: May 15, 2014.

3 Mincer J. E-cigarette Usage Surges in Past Year: Reuters/Ipsos Poll. www.reuters.com/article/ us-usa-ecigarette-poll-analysis-idUSKBN0OQ0CA20150610 Date last updated: June 10, 2015.

4 Carey C, Wang B, Johnson SE, et al. Centers for Disease Control and Prevention. Notes From the Field: Electronic Cigarette Use Among Middle and High School Students - United States, 2011-2012. MMWR; 62: 729-730.

5 Hua M, Alfi M, Talbot P. Health-related effects reported by electronic cigarette users in online forums. $J$ Med Internet Res 2013; 15: e59.

6 Rusznak C, Sapsford RJ, Devalia JL, et al. Interaction of cigarette smoke and house dust mite allergens on inflammatory mediator release from primary cultures of human bronchial epithelial cells. Clin Exp Allergy 2001; 31: 226-238.

7 Kode A, Yang SR, Rahman I. Differential effects of cigarette smoke on oxidative stress and proinflammatory cytokine release in primary human airway epithelial cells and in a variety of transformed alveolar epithelial cells. Respir Res 2006; 7: 132.

8 Comer DM, Elborn JS, Ennis M. Inflammatory and cytotoxic effects of acrolein, nicotine, acetylaldehyde and cigarette smoke extract on human nasal epithelial cells. BMC Pulm Med 2014; 14: 32.

9 Blake GH, Abell TD, Stanley WG. Cigarette smoking and upper respiratory infection among recruits in basic combat training. Ann Intern Med 1988; 109: 198-202.

10 US Food and Drug Administration. Summary of Results: Laboratory Analysis of Electronic Cigarettes Conducted by FDA. www.fda.gov/NewsEvents/PublicHealthFocus/ucm173146.htm Date last accessed: Dec 3, 2016. Date last updated: April 22, 2014. 

cigarettes ordinaires et de la chicha. [Comparison of the aerosol produced by electronic cigarettes with conventional cigarettes and the shisha]. Rev Mal Respir 2013; 30: 752-757.

12 Bhatnagar A, Whitsel LP, Ribisl KM, et al. Electronic cigarettes: a policy statement from the American Heart Association. Circulation 2014; 130: 1418-1436.

13 Kaisar MA, Prasad S, Liles T, et al. A decade of e-cigarettes: limited research and unresolved safety concerns. Toxicology 2016; 365: 67-75.

14 Trtchounian A, Williams M, Talbot P. Conventional and electronic cigarettes (e-cigarettes) have different smoking characteristics. Nicotine Tob Res 2010; 12: 905-912.

15 Williams M, Talbot P. Variability among electronic cigarettes in the pressure drop, airflow rate, and aerosol production. Nicotine Tob Res 2011; 13: 1276-1283.

16 Flouris AD, Chorti MS, Poulianiti KP, et al. Acute impact of active and passive electronic cigarette smoking on serum cotinine and lung function. Inhal Toxicol 2013; 25: 91-101.

17 Farsalinos KE, Spyrou A, Tsimopoulou K, et al. Nicotine absorption from electronic cigarette use: comparison between first and new-generation devices. Sci Rep 2014; 4: 4133.

18 Schroeder MJ, Hoffman AC. Electronic cigarettes and nicotine clinical pharmacology. Tob Control 2014; 23: Suppl. 2, ii30-ii35.

19 Foulds J, Veldheer S, Yingst J, et al. Development of a questionnaire for assessing dependence on electronic cigarettes among a large sample of ex-smoking E-cigarette users. Nicotine Tob Res 2015; 17: 186-192.

20 Kosmider L, Sobczak A, Fik M, et al. Carbonyl compounds in electronic cigarette vapors: effects of nicotine solvent and battery output voltage. Nicotine Tob Res 2014; 16: 1319-1326.

21 Cogliano VJ, Baan R, Straif K, et al. Preventable exposures associated with human cancers. J Natl Cancer Inst 2011; 103: 1827-1839.

22 Varlet V, Farsalinos K, Augsburger M, et al. Toxicity assessment of refill liquids for electronic cigarettes. Int Environ Res Public Health 2015; 12: 4796-4815.

23 Jensen RP, Strongin RM, Peyton DH. Solvent chemistry in the electronic cigarette reaction vessel. Sci Rep 2017; 7: 42549.

24 Bahl V, Lin S, Xu N, et al. Comparison of electronic cigarette refill fluid cytotoxicity using embryonic and adult models. Reprod Toxicol 2012; 34: 529-537.

25 Morgan DL, Flake GP, Kirby PJ, et al. Respiratory toxicity of diacetyl in C57BL/6 mice. Toxicol Sci 2008; 103: 169-180.

26 Zaccone EJ, Goldsmith WT, Shimko MJ, et al. Diacetyl and 2,3-pentanedione exposure of human cultured airway epithelial cells: ion transport effects and metabolism of butter flavoring agents. Toxicol Appl Pharmacol 2015; 289: 542-549.

27 Sherwood CL, Boitano S. Airway epithelial cell exposure to distinct e-cigarette liquid flavorings reveals toxicity thresholds and activation of CFTR by the chocolate flavoring 2,5-dimethypyrazine. Respir Res 2016; 17: 57.

28 Williams M, Villarreal A, Bozhilov K, et al. Metal and silicate particles including nanoparticles are present in electronic cigarette cartomizer fluid and aerosol. PLoS One 2013; 8: e57987.

29 Jugan ML, Barillet S, Simon-Deckers A, et al. Titanium dioxide nanoparticles exhibit genotoxicity and impair DNA repair activity in A549 cells. Nanotoxicology 2012; 6: 501-513.

30 Zhang Y, Sumner W, Chen DR. In vitro particle size distributions in electronic and conventional cigarette aerosols suggest comparable deposition patterns. Nicotine Tob Res 2013; 15: 501-508.

31 Mikheev VB, Brinkman MC, Granville CA, et al. Real-time measurement of electronic cigarette aerosol size distribution and metals content analysis. Nicotine Tob Res 2016; 18: 1895-1902.

32 Ferrari M, Zanasi A, Nardi E, et al. Short-term effects of a nicotine-free e-cigarette compared to a traditional cigarette in smokers and non-smokers. BMC Pulm Med 2015; 15: 120.

33 Misra $\mathrm{M}$, Leverette $\mathrm{R}$, Cooper $\mathrm{B}$, et al. Comparative in vitro toxicity profile of electronic and tobacco cigarettes, smokeless tobacco and nicotine replacement therapy products: e-liquids, extracts and collected aerosols. Int $J$ Environ Res Public Health 2014; 11: 11325-11347.

34 Putzhammer R, Doppler C, Jakschitz T, et al. Vapours of US and EU market leader electronic cigarette brands and liquids are cytotoxic for human vascular endothelial cells. PLoS One 2016; 11: e0157337.

35 Cervellati F, Muresan XM, Sticozzi C, et al. Comparative effects between electronic and cigarette smoke in human keratinocytes and epithelial lung cells. Toxicol In Vitro 2014; 28: 999-1005.

36 Higham A, Rattray NJ, Dewhurst JA, et al. Electronic cigarette exposure triggers neutrophil inflammatory responses. Respir Res 2016; 17: 56.

37 Wu Q, Jiang D, Minor M, et al. Electronic cigarette liquid increases inflammation and virus infection in primary human airway epithelial cells. PLoS One 2014; 9: e108342.

38 Sussan TE, Gajghate S, Thimmulappa RK, et al. Exposure to electronic cigarettes impairs pulmonary anti-bacterial and anti-viral defenses in a mouse model. PLoS One 2015; 10: e0116861.

39 Crotty Alexander LE, Enany S, Hwang H, et al. E-cigarettes May Boost Resistance of Drug-Resistant Pathogens. American Thoracic Society International Conference, San Diego, 2014.

40 Shen $\mathrm{Y}$, Wolkowicz MJ, Kotova $\mathrm{T}$, et al. Transcriptome sequencing reveals e-cigarette vapor and mainstream-smoke from tobacco cigarettes activate different gene expression profiles in human bronchial epithelial cells. Sci Rep 2016; 6: 23984.

41 Cressey D. E-cigarettes affect cells. Nature 2014; 508: 159.

42 Canistro D, Vivarelli F, Cirillo S, et al. E-cigarettes induce toxicological effects that can raise the cancer risk. Sci Rep 2017; 7: 2028.

43 Tweed JO, Hsia SH, Lutfy K, et al. The endocrine effects of nicotine and cigarette smoke. Trends Endocrinol Metab 2012; 23: 334-342.

44 Thorne D, Crooks I, Hollings $\mathrm{M}$, et al. The mutagenic assessment of an electronic-cigarette and reference cigarette smoke using the Ames assay in strains TA98 and TA100. Mutat Res 2016; 812: 29-38.

45 Sanner T, Grimsrud TK. Nicotine: carcinogenicity and effects on response to cancer treatment - a review. Front Oncol 2015; 5: 196. 
Monroy AE, Hommel E, Smith ST, et al. Paroxysmal atrial fibrillation following electronic cigarette use in an elderly woman. Clin Geriatr 2012; 20: 28-32.

47 Kivrak T, Sunbul M, Durmus E, et al. Acute myocardial infarction due to liquid nicotine in a young man. Ther Adv Cardiovasc Dis 2014; 8: 32-34.

48 Hua M, Talbot P. Potential health effects of electronic cigarettes: a systematic review of case reports. Prev Med Rep 2016; 4: 169-178.

49 Vardavas CI, Anagnostopoulos N, Kougias M, et al. Short-term pulmonary effects of using an electronic cigarette: impact on respiratory flow resistance, impedance, and exhaled nitric oxide. Chest 2012; 141 : $1400-1406$.

50 Ferrante G, Malizia V, Antona R, et al. The value of FeNO measurement in childhood asthma: uncertainties and perspectives. Multidiscip Respir Med 2013; 8: 50

51 Schober W, Szendrei K, Matzen W, et al. Use of electronic cigarettes (e-cigarettes) impairs indoor air quality and increases FeNO levels of e-cigarette consumers. Int J Hyg Environ Health 2014; 217: 628-637.

52 US Food and Drug Administration. The Facts on the FDA's New Tobacco Rule. Date last accessed: December 3 , 2016. Date last updated: June 16, 2016.

53 Barraza LF, Weidenaar KE, Cook LT, et al. Regulations and policies regarding e-cigarettes. Cancer 2017; 123: 3007-3014.

54 Clarke T, Mincer J. U.S. House Bill Would Exempt E-Cigarettes From Tobacco Regulations. Reuters, 2017.

55 Cheng T. Chemical evaluation of electronic cigarettes. Tob Control 2014; 23: Suppl. 2, ii11-ii17.

56 Buettner-Schmidt K, Miller DR. An observational study of compliance with North Dakota's smoke-free law among retail stores that sell electronic smoking devices. Tob Control 2017; 26, 452-454.

57 Farsalinos KE, Polosa R. Safety evaluation and risk assessment of electronic cigarettes as tobacco cigarette substitutes: a systematic review. Ther Adv Drug Saf 2014; 5: 67-86.

58 Sisler L, Meernik C, Ripley-Moffitt C, et al. Case study: use of electronic nicotine delivery systems (ENDS) by a pregnant woman. J Smok Cessat 2017; 12: 139-142.

59 Baeza-Loya S, Viswanath H, Carter A, et al. Perceptions about e-cigarette safety may lead to e-smoking during pregnancy. Bull Menninger Clin 2014; 78: 243-252.

60 Løchen ML. The electronic cigarette, do we need to worry? Eur Heart J 2017; 38: 1870.

61 Polosa R. Electronic cigarette use and harm reversal: emerging evidence in the lung. BMC Med 2015; 13 : 54.

62 Bullen C, McRobbie H, Thornley S, et al. Effect of an electronic nicotine delivery device (e cigarette) on desire to smoke and withdrawal, user preferences and nicotine delivery: randomised cross-over trial. Tob Control 2010; 19: 98-103.

63 Bullen C, Howe C, Laugesen M, et al. Electronic cigarettes for smoking cessation: a randomised controlled trial. Lancet 2013; 382: 1629-1637.

64 Rahman MA, Hann N, Wilson A, et al. E-cigarettes and smoking cessation: evidence from a systematic review and meta-analysis. PLoS One 2015; 10: e0122544.

65 Rigotti NA. Strategies to help a smoker who is struggling to quit. JAMA 2012; 308: 1573-1580.

66 Benowitz NL, Goniewicz ML. The regulatory challenge of electronic cigarettes. JAMA 2013; 310: 685-686.

67 McAuley TR, Hopke PK, Zhao J, et al. Comparison of the effects of e-cigarette vapor and cigarette smoke on indoor air quality. Inhal Toxicol 2012; 24: 850-857.

68 Lim HH, Shin HS. Measurement of aldehydes in replacement liquids of electronic cigarettes by headspace gas chromatography-mass spectrometry. Bull Korean Chem Soc 2013; 34: 2691-2696.

69 Goniewicz ML, Knysak J, Gawron M, et al. Levels of selected carcinogens and toxicants in vapour from electronic cigarettes. Tob Control 2014; 23: 133-139.

70 Fowles J, Bates, M, Noiton D. The Chemical Constituents in Cigarettes and Cigarette Smoke: Priorities for Harm Reduction. A Report to the New Zealand Ministry of Health. 2000.

71 National Research Council of the National Academies. Emergency and Continuous Exposure Guidance Levels for Selected Submarine Contaminants. Washington, DC, National Academies Press, 2009.

72 United States Environmental Protection Agency. Acetaldehyde Hazard Summary. Washington, DC, United States Environmental Protection Agency, 2000.

73 Feron VJ, Kruysse A, Woutersen RA. Respiratory tract tumours in hamsters exposed to acetaldehyde vapour alone or simultaneously to benzo(a)pyrene or diethylnitrosamine. Eur J Cancer Clin Oncol 1982; 18: 13-31.

74 Setshedi M, Wands JR, Monte SM. Acetaldehyde adducts in alcoholic liver disease. Oxid Med Cell Longev 2010; 3: $178-185$.

75 Lieber CS. Metabolic effects of acetaldehyde. Biochem Soc Trans 1988; 16: 241-247.

76 Uchiyama S, Inaba Y, Kunugita N. Determination of acrolein and other carbonyls in cigarette smoke using coupled silica cartridges impregnated with hydroquinone and 2,4-dinitrophenylhydrazine. J Chromatogr A 2010; 1217: 4383-4388.

77 Laugesen M. Safety Report on the Ruyan ${ }^{\oplus}$ e-Cigarette Cartridge and Inhaled Aerosol. Christchurch, Health New Zealand, 2008.

78 US Department of Health and Human Services, Public Health Service, Agency for Toxic Substances and Disease Registry. Toxicological Profile for Acetone. Atlanta, GA, US Department of Health and Human Services, Public Health Service, 1994.

79 Talhout R, Schulz T, Florek E, et al. Hazardous compounds in tobacco smoke. Int J Environ Res Public Health 2011; 8: 613-628.

80 Harris JE. Cigarette Smoke Components and Disease: Cigarette Smoke is More than a Triad of Tar, Nicotine, and Carbon Monoxide. Bethesda, National Cancer Institute, 1996.

81 Agency for Toxic Substances and Disease Registry. Medical Management Guidelines for Acrolein. www.atsdr.cdc. gov/MMG/MMG.asp?id=552\&tid=102 Date last accessed: June 11, 2017. Date last updated: Oct 21, 2014.

82 Moghe A, Ghare S, Lamoreau B, et al. Molecular mechanisms of acrolein toxicity: relevance to human disease. Toxicol Sci 2015; 143: 242-255.

83 Agency for Toxic Substances and Disease Registry. Cadmium: Regulations, Advisories, and Guidelines. Atlanta Agency for Toxic Substances and Disease Registry, 1987.

84 Kippler M, Tofail F, Gardner R, et al. Maternal cadmium exposure during pregnancy and size at birth: a prospective cohort study. Environ Health Perspect 2012; 120: 284-289. 
Godt J, Scheidig F, Grosse-Siestrup C, et al. The toxicity of cadmium and resulting hazards for human health. J Occup Med Toxicol 2006; 1: 22.

Huff J, Lunn RM, Waalkes MP, et al. Cadmium-induced cancers in animals and in humans. Int J Occup Environ Health 2007; 13: 202-212.

Rani A, Kumar A, Lal A, et al. Cellular mechanisms of cadmium-induced toxicity: a review. Int J Environ Health Res 2014; 24: 378-399.

Jin T, Lu J, Nordberg M. Toxicokinetics and biochemistry of cadmium with special emphasis on the role of metallothionein. Neurotoxicology 1998; 19: 529-535.

Occupational Safety and Health Administration. Occupational Safety and Health Standards-Chromium. Washington DC, United States Department of Labor, 2012.

De Mattia G, Bravi MC, Laurenti O, et al. Impairment of cell and plasma redox state in subjects professionally exposed to chromium. Am J Ind Med 2004; 46: 120-125.

Agency for Toxic Substances and Disease Registry. Medical Management Guidelines for Formaldehyde. www.atsdr.cdc. gov/MMG/MMG.asp?id=216\&tid=39 Date last accessed: June 12, 2017. Date last updated: Oct 21, 2014. 2014; 27: 1081-1091.

Goniewicz ML, Kuma T, Gawron M, et al. Nicotine levels in electronic cigarettes. Nicotine Tob Res 2013; 15: 158-166.

Centers for Disease Control and Prevention. Nicotine: Systemic Agent. www.cdc.gov/niosh/ershdb/ emergencyresponsecard_29750028.html Date last accessed: June 12, 2017. Date last updated: Nov 9, 2017.

England LJ, Bunnell RE, Pechacek TF, et al. Nicotine and the developing human: a neglected element in the electronic cigarette debate. Am J Prev Med 2015; 49: 286-293.

Kovacic P, Cooksy A. Iminium metabolite mechanism for nicotine toxicity and addiction: oxidative stress and electron transfer. Med Hypotheses 2005; 64: 104-111.

Farren NJ, Ramírez N, Lee JD, et al. Estimated exposure risks from carcinogenic nitrosamines in urban airborne particulate matter. Environ Sci Technol 2015; 49: 9648-9656.

Hebels DG, Briedé JJ, Khampang R, et al. Radical mechanisms in nitrosamine- and nitrosamide-induced whole-genome gene expression modulations in Caco-2 cells. Toxicol Sci 2010; 116: 194-205.

Occupational Safety and Health Administration. Toxic and Hazardous Substances, Standard-29CFR. Washington DC, United States Department of Labor, 2017.

Rosenberg NL, Spitz MC, Filley CM, et al. Central nervous system effects of chronic toluene abuse - clinical, brainstem evoked response and magnetic resonance imaging studies. Neurotoxicol Teratol 1988; 10: 489-495.

Cruz SL, Rivera-Garcia MT, Woodward JJ. Review
molecular targets. J Drug Alcohol Res 2014; 3: 235840.

National Institute for Occupational Safety and Health. Lead. Information for Employers: Lead Exposure Limits. www.cdc.gov/niosh/topics/lead/limits.html Date last accessed: June 18, 2017. Date last updated: April 19, 2017. Wani AL, Ara A, Usmani JA. Lead toxicity: a review. Interdiscip Toxicol 2015; 8: 55-64.

Flora G, Gupta D, Tiwari A. Toxicity of lead: a review with recent updates. Interdiscip Toxicol 2012; 5: 47-58. 